DOI: 10.1002/adma.200700837

\title{
Efficient Solar Cells Using All-Organic Nanocrystalline Networks**
}

\author{
By Fan Yang, Kai Sun, and Stephen R. Forrest*
}

The power conversion efficiencies of organic photovoltaic (PV) cells have steadily increased since the introduction of the donor/acceptor (DA) heterojunction. ${ }^{[1]}$ Further improvements have been reported in entangled or "bulk-heterojunction" (BHJ) structures, where the DA interface is within an exciton diffusion length $(\sim 10 \mathrm{~nm})$ of the site for photon absorption. ${ }^{[2]}$ However, the high series resistance ${ }^{[3,4]}$ of these amorphous blends limits the active layer thickness, leading to low fill factor and reduced light absorption, and hence a low solar energy conversion efficiency. ${ }^{[5]}$ One means to circumvent the low mobility of charge in disordered organic films has been the use of inorganic semiconductor "quantum dots". ${ }^{[6]}$ These nanocrystals serve as charge generation sites that, when loaded into a polymer film at high density, can form a high conductivity percolating path to extract photogenerated charge from the device active region. Unfortunately, the mismatch in optical and excitonic properties between the quantum dots and the polymer matrix has limited PV cell efficiencies of photovoltaic cells based on these materials. In this work, we demonstrate that controlled crystallization of organic molecules results in a PV cell in which the active layer comprises a nanocrystalline organic region that forms high conductivity networks for charge extraction. This cell shares many of the benefits of organic/inorganic quantum dot cells as well as all-organic bulk heterojunctions without many of their disadvantages. Structural analysis confirms the existence of

[*] Prof. S. R. Forrest, F. Yang

Department of Electrical Engineering \& Computer Science

University of Michigan, Ann Arbor, MI 48109 (USA)

E-mail: stevefor@umich.edu

S. R. Forrest, K. Sun

Department of Materials Science \& Engineering, University of Michigan

Ann Arbor, MI 48109 (USA)

S. R. Forrest

Department of Physics, University of Michigan

Ann Arbor, MI 48109 (USA)

F. Yang

Department of Electrical Engineering, Princeton University

Princeton, NJ 08544 (USA)

K. Sun

Electron Microbeam Analysis Laboratory, University of Michigan Ann Arbor, MI 48109 (USA)

$[* *$ ] The authors gratefully acknowledge Barry P. Rand and Jay B. Benziger for helpful discussions, and Guodan Wei for absorption measurements. We also thank the US Air Force Office of Scientific Research and Clobal Photonic Energy Corporation for financial support. crystalline phases of the constituent donor molecule, copper phthalocyanine $(\mathrm{CuPc})$, and the acceptor, $\mathrm{C}_{60}$. The new device architecture results in a three-fold increase of power conversion efficiency over that of an efficient planar HJ solar cell control.

To reduce cell series resistance in the organic $\mathrm{BHJ}$ it is necessary to create morphological order that leads to a low resistance to charge conduction, lacking bottlenecks or islands that impede carrier extraction. Indeed, spatial ordering induced by vertical phase separation led to increased charge collection in organic/inorganic quantum dot hybrid cells from $1.7 \%^{[6]}$ for a disordered cell to $2.8 \%{ }^{[7]}$ For this reason, we recently reported organic solar cells with an ordered, interdigitated DA interface formed by crystalline donor protrusions and a planarizing acceptor layer, grown by the process of organic vapor phase deposition (OVPD). Control of organic film crystallization and morphology resulted in a low resistance, ordered, interdigitated interface that, when employed in solar cell structures, led to significantly improved efficiency over otherwise identical planar HJs. ${ }^{[8]}$ Such an interface, however, does not increase efficiency for the materials with large exciton diffusion lengths, e.g., $\mathrm{C}_{60}$, where the finite protrusion size and density do not lead to increased exciton dissociation. ${ }^{[9]}$ In the current work, we have expanded the DA crystalline interface concept into an extended bulk, highly interconnected and entangled interpenetrating network. This concept employing a thicker DA region significantly increases the HJ interface area while maintaining crystalline regions that effectively conduct charges to the opposing electrodes of the cells. This architecture opens up a range of possibilities for attaining high efficiency organic PV cells, including the mixing of three or more organic constituents in a single active region to provide full coverage of the solar spectrum.

The nanocrystalline network relies on the growth of ultrathin, alternating layers of the D and A molecules such that any given layer does not fully cover the layer that lies below. Incomplete coverage results from a combination of lack of surface wetting, and control of film morphology and crystalline texture using OVPD (see Experimental).

The growth of nanocrystalline DA networks was simulated by including gas phase molecular transport, surface diffusion, and re-evaporation back into gas phase,$^{[10]}$ with results shown in Figure 1a. Periodic boundary conditions apply in both inplane directions. Organic molecules randomly originate far from the substrate in the gas phase, and diffuse toward the substrate. Upon reaching a solid surface, the admolecule diffuses on the solid film surface, where the jumping rate be- 

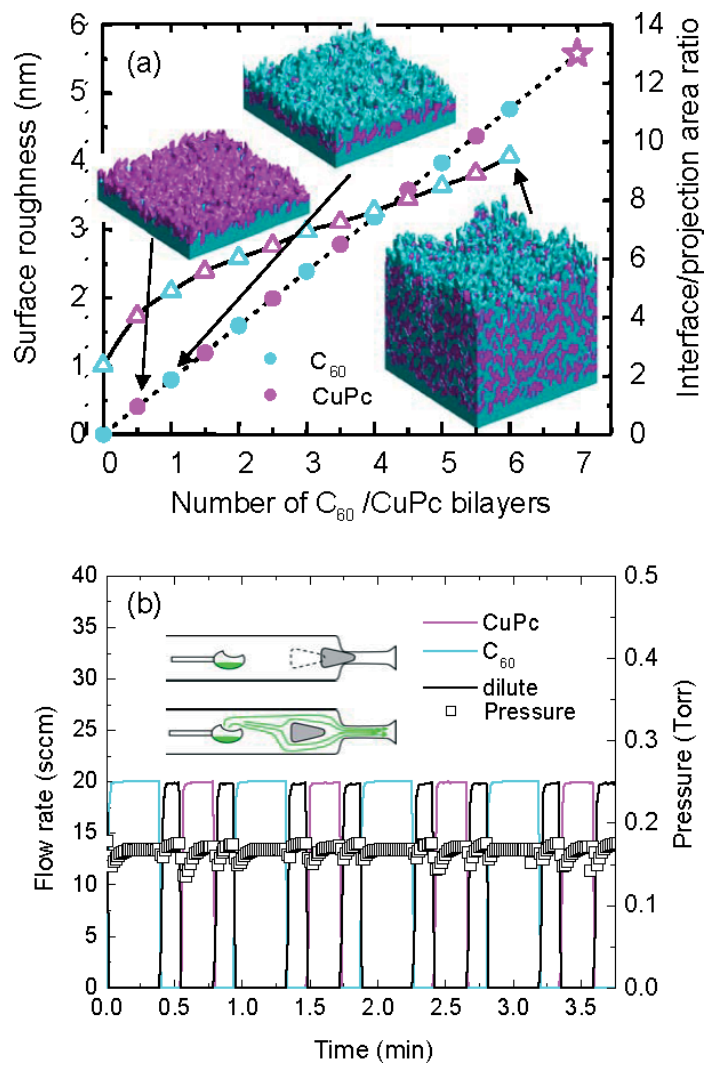

Figure 1. Simulation and growth methods of $\left[\mathrm{C}_{60}(3 \mathrm{~nm}) / \mathrm{CuPc}(3 \mathrm{~nm})\right]_{n}$ nanocrystalline donor/acceptor (DA) networks. a) Simulation of the growth progression of a six period network. The plot shows, the root mean square (rms) surface roughness (open triangles) and the interface area relative to a planar DA junction (filled circles) as functions of number of bilayers. The star shows the final area ratio after the 6-period network is covered by a continous $C_{60}$ planarizing layer. The three inset pictures show the evolution of the film structure and surface morphology of the $\mathrm{C}_{60}$ (magenta)/CuPc (cyan) nanocrystals at different growth stages in the progression, as well as the CuPc network formed after the sixth $\mathrm{C}_{60} / \mathrm{CuPc}$ cycle, where 3-D interconnected networks can be clearly seen. b) Mass flow rates and pressure change recorded during the organic vapor phase deposition of the $\mathrm{C}_{60} / \mathrm{CuPc}_{\mathrm{P}}$ structure. Top inset: Barrel valve in the off position, preventing organics from diffusing out of the barrel. Bottom inset: Carrier gas conveying organic molecules out of the barrel when the valve is in the on position.

tween two sites, $i$ and $j$, is determined by the site energy $E_{i}$ and $E_{j}$ as ${ }^{[10]}$

$K_{1 \rightarrow j}=v f\left(E_{i}, E_{j}\right)$

Here $v$ is the lattice vibration factor and

$f\left(E_{i}, E_{j}\right)=\left\{\begin{array}{cc}\exp \left(\frac{-E_{j}-E_{i}}{k_{B} T}\right) & \text { if } E_{j}>E_{i} \\ 1 & \text { if } E_{j}>E_{i}\end{array}\right.$

The site energy, $E_{i}$, is the sum of van der Waals interactions between the admolecule and all proximal neighboring mole- cules. The interaction energies between nearest neighbors are taken as $0.867 \mathrm{eV}(\mathrm{CuPc}-\mathrm{CuPc}),{ }^{[11]} 1.5 \mathrm{eV}\left(\mathrm{C}_{60}-\mathrm{C}_{60}\right),{ }^{[12,13]}$ and $0.044 \mathrm{eV}\left(\mathrm{CuPc}-\mathrm{C}_{60}\right){ }^{[14]}$ respectively. Since the interaction between like molecules is much larger than the interaction between unlike molecular pairs, similar molecules tend to aggregate. The simulated growth of the network begins on a continuous layer of $\mathrm{CuPc}$ on a transparent conductive substrate, e.g., indium-tin-oxide (ITO). Then a thin layer of $\mathrm{C}_{60}$ is deposited on top of the underlying, continuous $\mathrm{CuPc}$ layer. The aggregates in the $\mathrm{C}_{60}$ layer do not provide a full coverage of the underlayer, leaving part of the $\mathrm{CuPc}$ exposed. A second, thin $\mathrm{CuPc}$ layer is then deposited, partially covering the $\mathrm{C}_{60}$ layer with portions of the second $\mathrm{CuPc}$ layer directly contacting the first, continuous CuPc layer. By continuously alternating the deposition of $\mathrm{C}_{60}$ and $\mathrm{CuPc}, 3 \mathrm{D}$ interpenetrating nanocrystalline networks of $\mathrm{C}_{60}$ and $\mathrm{CuPc}$ are formed. The growth simulation indicates a monotonic increase of the interface area as the number of alternating DA bilayers is increased. As shown in Figure 1a, the final interface area in a nanocrystalline cell with $6 \mathrm{C}_{60} / \mathrm{CuPc}$ pairs is 11 times that of a planar interface. The root mean square (rms) surface roughness of the nanocrystlline films also increases, and reaches a maximum of approximately $4 \mathrm{~nm}$. The final step is the growth of a continuous $\mathrm{C}_{60}$ layer on top of the network, planarizing the film surface to prevent shorts. ${ }^{[8]}$

We used OVPD to grow the crystalline network PV cells. Large nitrogen gas flow rates $(150 \mathrm{sccm}$ for $\mathrm{CuPc}$ and 100 for $\left.\mathrm{C}_{60}\right)$ and low substrate temperatures $\left(T_{\text {sub }}=4 \pm 1^{\circ} \mathrm{C}\right)$ were used for the bottom and top continuous layers, resulting in a flat surface. Smaller nitrogen flow rates $(20 \mathrm{sccm}$ for both $\mathrm{CuPc}$ and $\left.\mathrm{C}_{60}\right)$ and higher $T_{\text {sub }}\left(15 \pm 1^{\circ} \mathrm{C}\right)$ were used to promote crystallization during the discontinuous layer growth. ${ }^{[15]}$ The crystalline film texture of an OVPD-grown multilayer (grown by the process illustrated in Figure 1b, and described in the Experimental) is confirmed by transmission electron microscopy (TEM), X-ray diffraction (XRD) and atomic force microscopy (AFM), as shown in Figure 2. A cross-sectional TEM image of $\left[\mathrm{CuPc}(6.1 \mathrm{~nm}) / \mathrm{C}_{60}(6.1 \mathrm{~nm})\right]_{10}$ is shown in Figure 2a. (Here, the notation $[\mathrm{D}(x \mathrm{~nm}) / \mathrm{A}(y \mathrm{~nm})]_{n}$ refers to the thicknesses $x, y$ of the $\mathrm{D}$ and A layers, respectively, and $n$ is the number of DA pairs.) The CuPc and $\mathrm{C}_{60}$ phases are similar to those observed in a crystalline bilayer film. ${ }^{[16]}$ The $\mathrm{C}_{60}$ phase has clearly ordered, close packed molecular planes, while the monoclinic CuPc lattice appears less ordered since the image is not taken along the projection of a single, crystallographic plane. ${ }^{[17]}$ Both electron and X-ray diffraction confirm the existence of crystalline domains of $\mathrm{CuPc}$ and $\mathrm{C}_{60}$. Crystalline domain sizes range from $5 \mathrm{~nm}$ to $10 \mathrm{~nm}$, similar to those found in homogeneous films of $\mathrm{C}_{60}$ but smaller than $\mathrm{ZnPc}$ crystals obtained by thermal evaporation ${ }^{[18,19]}$. We obtained similar TEM images of $\left[\mathrm{CuPc}(3.1 \mathrm{~nm}) / \mathrm{C}_{60}(3.1 \mathrm{~nm})\right]_{17}$, where the crystallites are similar in shape but have slightly smaller sizes, as expected. High-angle annular dark-field images confirm the presence of $\mathrm{CuPc}$ aggregates, with sizes comparable to the domain sizes observed in Figure 2a. 

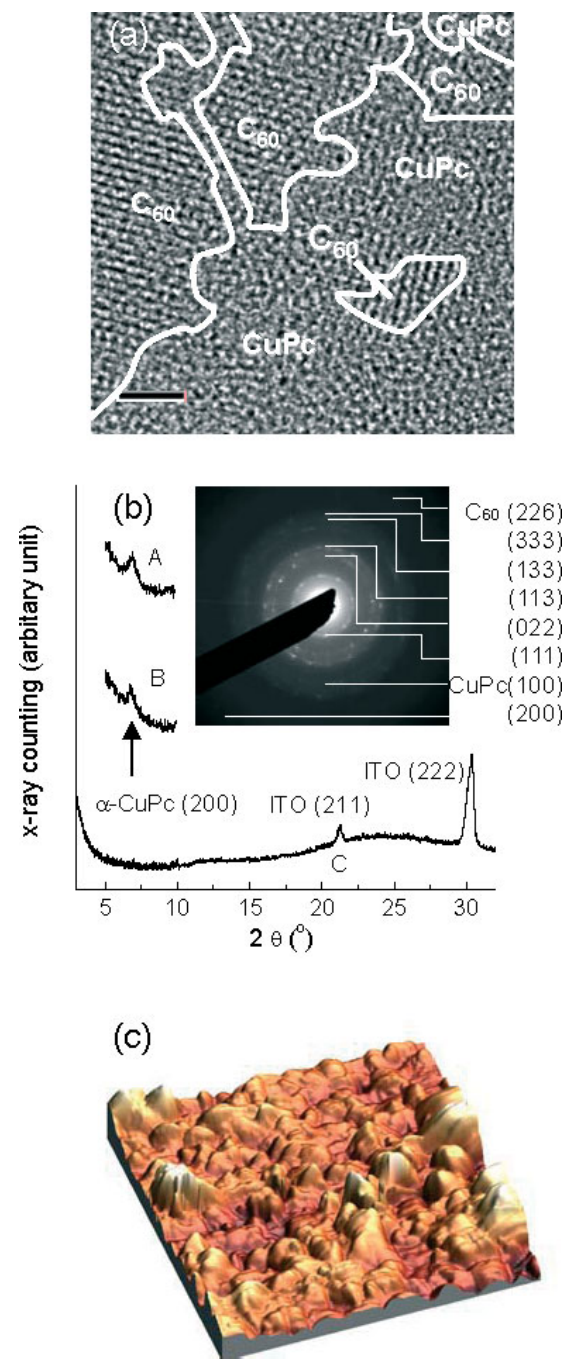

Figure 2. Structural characterization of a $\mathrm{C}_{60} / \mathrm{CuPc}$ nanocrystalline film grown on an indium-tin-oxide (ITO) substrate. a) Cross sectional highresolution TEM image of a $\left[\mathrm{CuPc}(6.1 \mathrm{~nm}) / \mathrm{C}_{60}(6.1 \mathrm{~nm})\right]_{10}$ film, showing nanocrystalline domains indicated by white curves that approximately locate the domain boundaries. The scale bar corresponds to $5 \mathrm{~nm}$. b) Bragg-Brentano $x$-ray diffraction pattern of an OVPD grown $A$. $\left[\mathrm{C}_{60}(3.5 \mathrm{~nm}) / \mathrm{CuPc}(3.5 \mathrm{~nm})\right]_{5}$ film, and B. a $\left[\mathrm{C}_{60}(1.9 \mathrm{~nm}) /\right.$ CuPc $(1.9 \mathrm{~nm})]_{10}$ film. C. A $100-\mathrm{nm}$ thick $\mathrm{C}_{60}: \mathrm{CuPc}=1: 1 \mathrm{mixed}$ film grown by vacuum thermal coevaporation. The CuPc (200) and ITO (211), (222) indices are indicated. The lack of a CuPc peak in C. indicates the absence of crystalline domains. Inset: Plan-view selective area diffraction pattern taken for the film in a. The diffraction indicies of $\alpha$-CuPc and $\mathrm{C}_{60}$ are marked. Well defined diffraction spots indicating a high degree of crystalline order. c) Atomic force micrscopic surface morphology of the same film in a, showing an rms roughness of $12.7 \mathrm{~nm}$ in the $100 \times 100 \mathrm{~nm}^{2}$ area.

A selected-area electron diffraction (SAED) image of the same $\left[\mathrm{CuPc}(6.1 \mathrm{~nm}) / \mathrm{C}_{60}(6.1 \mathrm{~nm})\right]_{10}$ film in plan-view (Fig. 2b, inset) shows diffraction spots corresponding to ordered domains of $\alpha-\mathrm{CuPc}^{[20]}$ and face-centered cubic (fcc) $\mathrm{C}_{60} \cdot{ }^{[21]}$ The crystallites have a similar size and distribution as those seen in cross-sectional view. The well defined diffraction spots indicate a high degree of crystalline order and orientation within the region of the probe beam. In addition, the XRD patterns of $\left[\mathrm{CuPc}(3.5 \mathrm{~nm}) / \mathrm{C}_{60}(3.5 \mathrm{~nm})\right]_{5}$ and $[\mathrm{CuPc}(1.9 \mathrm{~nm}) /$ $\left.\mathrm{C}_{60}(1.9 \mathrm{~nm})\right]_{10}$ shown in Figure $2 \mathrm{~b}$, confirm the existence of $\alpha$-CuPc in the two samples. No $\mathrm{C}_{60}$ diffraction peaks can be identified in the scanning range owing to its large lattice constant $(a=14.16 \AA) .{ }^{[21]}$ These structural studies show that crystalline phases are obtained by alternating the growth of the $\mathrm{D}$ and A materials using OVPD, as opposed to amorphous CuPc: $\mathrm{C}_{60}$ mixed films grown by co-evaporation ${ }^{[4]}$ (bottom scan, Fig. 2b), where the crystalline phase separation is limited. $^{[4,5,18,19,22]}$ As shown in Figure 2c, the surface morphology of the same $\left[\operatorname{CuPc}(6.1 \mathrm{~nm}) / \mathrm{C}_{60}(6.1 \mathrm{~nm})\right]_{10}$ film observed by AFM shows the crystalline texture with an rms roughness of $12.7 \mathrm{~nm}$, reflecting the roughing effect (c.f. Fig. 1a) caused by the crystallite growth over the ITO substrate whose rms roughness $<3 \mathrm{~nm}$.

The absorption spectra of the nanocrystalline films are fit to the linear sum of the neat $\mathrm{CuPc}$ and $\mathrm{C}_{60}$ absorption spectra ( $\alpha_{\mathrm{CuPc}}$ and $\alpha_{\mathrm{C} 60}$, respectively). Figure $3 \mathrm{a}$ shows the absorption coefficient of $\left[\mathrm{CuPc}(3.1 \mathrm{~nm}) / \mathrm{C}_{60}(3.1 \mathrm{~nm})\right]_{17}$ grown on a fused quartz substrate, fit using $\alpha_{\mathrm{NC}}=0.48 \alpha_{\mathrm{C} 60}+0.23 \alpha_{\mathrm{CuPc}}$. Films with different DA cycle thicknesses are fit using similar expres-
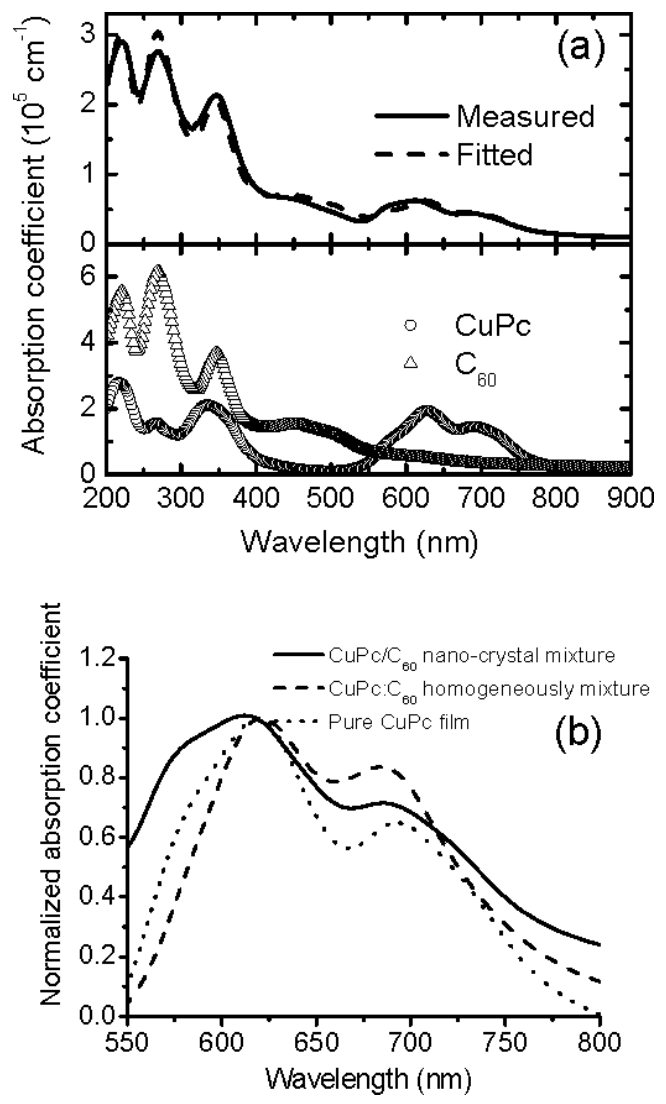

Figure 3. Absorption coefficients $(\alpha)$ of $\mathrm{CuPc}$ and $\mathrm{C}_{60}$ films on fused silica substrates. a) Absorption of a nanocrystalline $\left[C_{60}(3.1 \mathrm{~nm}) /\right.$ $\operatorname{CuPc}(3.1 \mathrm{~nm})]_{17}$ film, and a fit by $\alpha_{\mathrm{NC}}=0.48 a_{\mathrm{C} 60}+0.23 a_{\mathrm{CuPc}}$. The absorption of the pure films are shown in the lower part of the figure. b) Normalized absorption spectra in the low-energy Q-band of CuPc. 
sions. Pure $\mathrm{CuPc}$ films have two peaks centered at wavelengths of $\lambda=620$ and $695 \mathrm{~nm}$, corresponding to dimer and monomer absorption, respectively. ${ }^{[20]}$ For amorphous $\mathrm{CuPc}: \mathrm{C}_{60}$ mixtures, the absorption at $\lambda=695 \mathrm{~nm}$ is enhanced due to an increased intermolecular distance. ${ }^{[4,22,23]}$ By comparison, the nanocrystalline layer peak at $\lambda=695 \mathrm{~nm}$ is less pronounced than in the mixed film, implying the presence of a high density of $\mathrm{CuPc}$ crystallites (Fig. 3b). ${ }^{[22]}$ The asymmetry in the $\mathrm{CuPc}$ and $\mathrm{C}_{60}$ absorption obtained in our fits may be an effect of differing crystal sizes for these two molecular constituents.

We note that these crystalline structures are in a stable, rather than metastable, structures, as observed in annealed mixtures of $\mathrm{CuPc}$ and 3,4,9,10-perylenetetracarboxylic bisbenzimidazole (PTCBI) ${ }^{[24]}$ Furthermore, compared to phaseseparated polymer cells prepared by annealing at 110 $150^{\circ} \mathrm{C},{ }^{[3,15]}$ the small molecular weight films in our PV cells have high glass transition temperatures $\left(>400^{\circ} \mathrm{C}\right)$. Further phase separation of these cells is, therefore, not expected to occur under normal operating conditions and required operational lifetimes (10-20 years) of such devices.

A series of $\mathrm{CuPc}(14.5 \pm 0.2 \mathrm{~nm}) /\left[\mathrm{C}_{60}(3.2 \pm 0.2 \mathrm{~nm}) /\right.$ $\mathrm{CuPc}(3.2 \pm 0.2 \mathrm{~nm})]_{n} / \mathrm{C}_{60}(40.0 \pm 0.5 \mathrm{~nm}) / \mathrm{BCP}(10 \mathrm{~nm}) / \mathrm{Ag}$

$(\mathrm{BCP}=$ bathocuproine $)$ double heterojunction $\mathrm{PV}$ cells ${ }^{[25]}$ were fabricated, where $n$ ranged from 0 to 12 . Here, BCP was used as an exciton blocking layer. The nominal thicknesses of the $\mathrm{C}_{60}(3.2 \mathrm{~nm}) / \mathrm{CuPc}(3.2 \mathrm{~nm})$ multilayers were varied between 6.4 and $76.8 \mathrm{~nm}$, keeping $\mathrm{C}_{60}: \mathrm{CuPc}=1$ for all samples. Hence, for $n=12$, the total organic active film thickness was $t$ $=141 \mathrm{~nm}$, which exceeds $t=100 \mathrm{~nm}$, typical of that of a conventional, bilayer small molecular weight cell. This in turn increases the optical absorption because of its exponential dependence on thickness (i.e., cell responsivity follows $(1-\exp [-\alpha t]))$, where $\alpha$ is the absorption coefficient of the organic material. Furthermore, the top $\mathrm{C}_{60}$ layer is thicker than used in the optimized bilayer device, ${ }^{[25,26]}$ as necessary to planarize the rough film surface ${ }^{[8]}$ (c.f. Fig. 2c).

The dark current density-voltage $(J-V)$ characteristics of all cells have rectification ratios $>10^{4}$ at $\pm 1 \mathrm{~V}$, as shown in Figure $4 \mathrm{a}$. Fitting the forward $J-V$ curves using the ideal diode equation $^{[8,26]}$ yields the specific series resistance, $R_{\mathrm{SA}}$, as a function of the number of alternating DA pairs (and hence total active layer thickness) in Figure $4 \mathrm{~b}$. The bilayer $(n=0)$ cell has $R_{\mathrm{SA}}=0.5 \Omega \cdot \mathrm{cm}^{2}$, gradually increasing to $3.0 \Omega \cdot \mathrm{cm}^{2}$ for $n=12$. That $R_{\mathrm{SA}}$ increases by a factor of $\sim 6$ for a cell only twice as thick indicates that the nanocrystalline region is not completely free of bottlenecks to charge conduction. However, multilayers with fewer periods show only a 2 to 3 times increase in $R_{\mathrm{SA}}$, suggesting that disorder increases significantly only for the deepest stacks.

The photoresponse of the same cells as in Figure 4 measured under simulated $100 \pm 4 \mathrm{~mW} \mathrm{~cm}^{-2}$ AM $1.5 \mathrm{G}$ solar irradiation are shown in Figure 5a. The short circuit current $\left(J_{\mathrm{SC}}\right)$, open circuit voltage $\left(V_{\mathrm{OC}}\right)$, and fill factor $(F F)$ are plotted in Figure $5 \mathrm{~b}$. With $n$ increasing from 2 to $6, J_{\mathrm{SC}}$ significantly increases by nearly a factor of 3 , from $5.6 \pm 0.1 \mathrm{~mA} \mathrm{~cm}^{-2}$ in the bilayer cell to $17.0 \pm 0.2 \mathrm{~mA} \mathrm{~cm}^{-2}$, and then drops as $n$ is in-
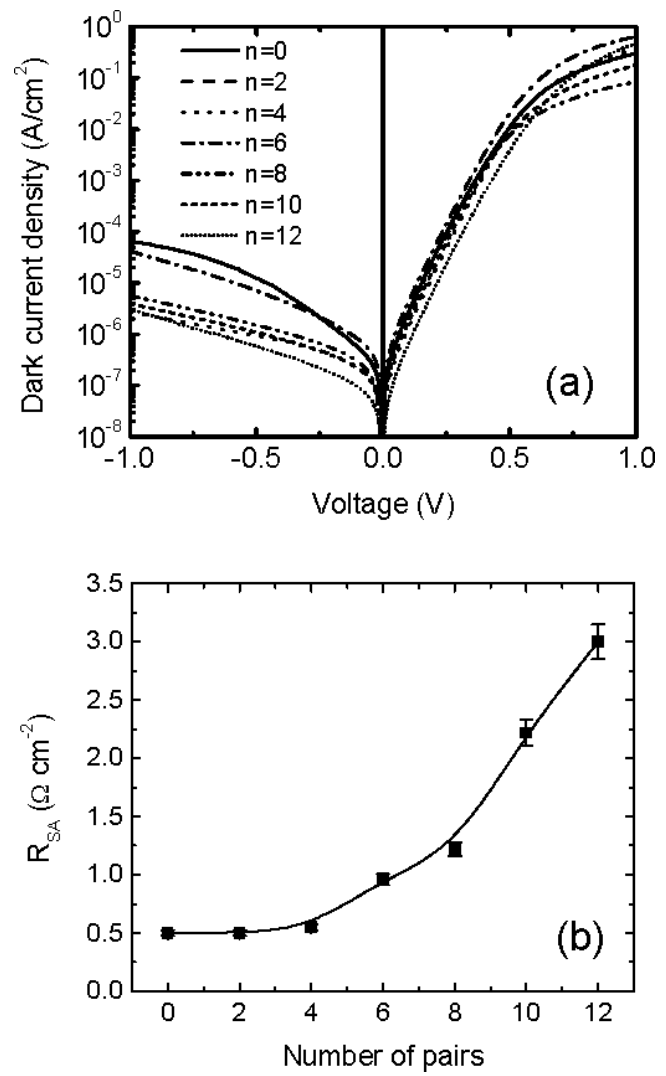

Figure 4. The performance of $\operatorname{CuPc}(14.5 \pm 0.2 \mathrm{~nm}) /\left[\mathrm{C}_{60}(3.2 \pm 0.2 \mathrm{~nm}) /\right.$ CuPc $(3.2 \pm 0.2 \mathrm{~nm})]_{\mathrm{n} /} \mathrm{C}_{60}(50.0 \pm 0.5 \mathrm{~nm}) / \mathrm{BCP}(10 \mathrm{~nm}) / \mathrm{Ag}$ solar cells, with $n$ varying from 0 to 12 , and the total thickness of the active layers varying from 54.5 to $141 \mathrm{~nm}$.. a. Dark current density-applied voltage $(J-V)$ characteristics b. Specific resistance $\left(R_{\mathrm{sa}}\right)$ as a function of $n$ and $\mathrm{C}_{60} / \mathrm{CuPc}$ nanocrystalline layer thickness, calculated by fitting the dark $J-V$ characteristics using the ideal diode equation.

creased further, owing to the high series resistance of the thickest cells with large and entangled crystalline networks. In the same figure, $V_{\mathrm{OC}}$ increases from $0.44 \pm 0.01 \mathrm{~V}$ in the bilayer cell $(n=0)$, and gradually increasing to $0.50 \pm 0.01 \mathrm{~V}$ at $n=12$. Finally, $F F$ decreases slightly from $0.57 \pm 0.01$ at $n=0$ to 0.56 at $n=6$, and drops to $0.44 \pm 0.01$ at $n=12$, once more reflecting the increase of resistance in the deepest stacks, as shown in Figure 4b.

The external quantum efficiency (EQE) as a function of wavelength ${ }^{[27]}$ is shown in Figure $5 \mathrm{c}$. The EQE peak, centered between $\lambda=430$ and $470 \mathrm{~nm}$, results from $\mathrm{C}_{60}$ absorption, ${ }^{[28]}$ whereas the peaks at $\lambda=620$ and $695 \mathrm{~nm}$ are due to CuPc absorption $^{[4]}$ (c.f. Fig. 3a). As the number of $\mathrm{C}_{60} / \mathrm{CuPc}$ pairs increases from $n=0$ to $n=6$, the EQE increases rapidly, i.e., the $\lambda=620 \mathrm{~nm}$ peak increases from $25 \%$ to $76 \%$, and the peak at $\lambda=450 \mathrm{~nm}$ increases from $22 \%$ to $64 \%$, both showing a 3 -fold increase with $n$. In fact, in a previously reported photodetector composed of continuous ultrathin $(\geq 0.5 \mathrm{~nm})$ $\mathrm{CuPc} / \mathrm{PTCBI}$ multilayer stacks grown in vacuum, an EQE of up to $75 \%$ was achieved at a reverse bias of $-10 \mathrm{~V}^{[29]}$ In contrast to that device, the nanocrystalline solar cell with its en- 

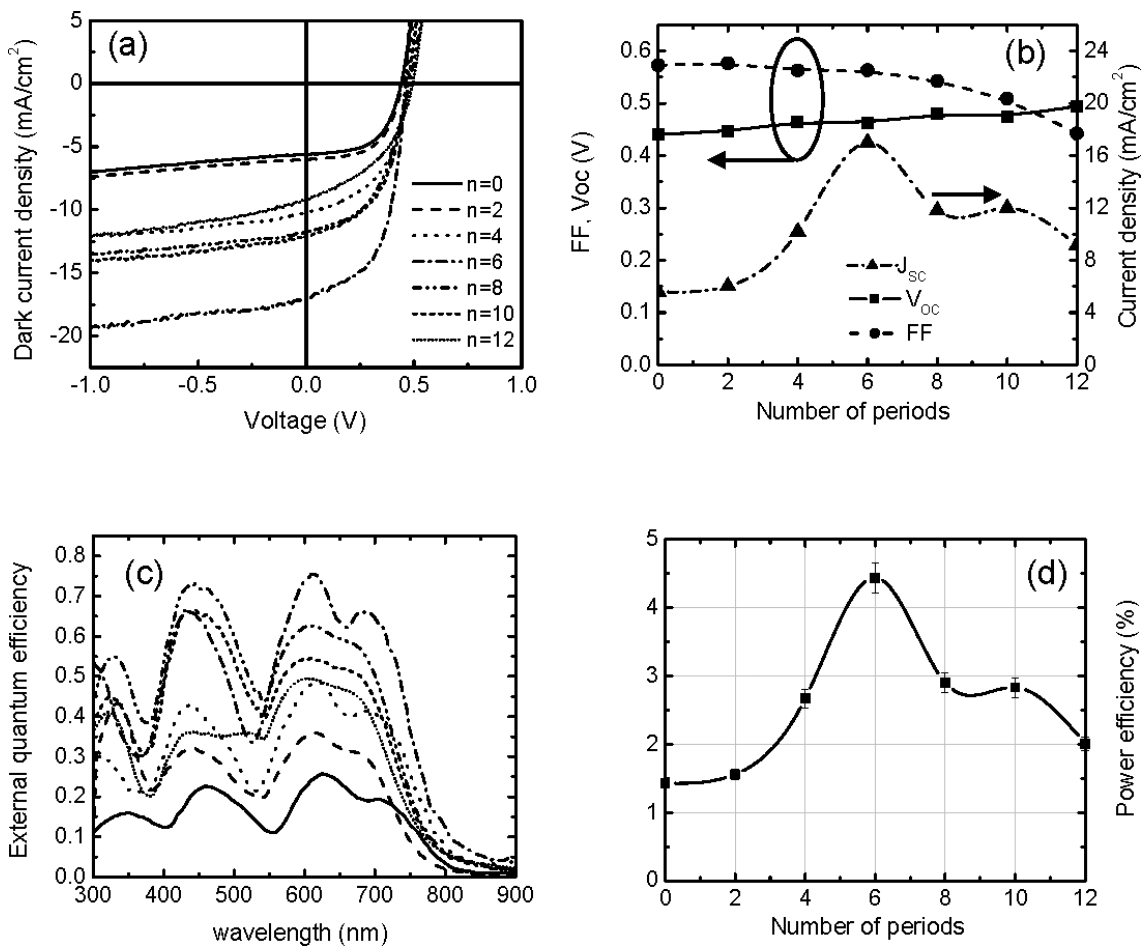

Figure 5. Parameters affecting room-temperature power-conversion efficiency of the solar cells in Figure 4. a) $J-V$ characteristics at simulated $A M 1.5$ global $105 \pm 5 \mathrm{~mW} \mathrm{~cm}^{-2}$ solar illumination. b) Short circuit current density $\left(U_{\mathrm{sc}}\right)$, open circuit voltage $\left(V_{O C}\right)$ and fill factor $(F F)$ as functions of the number of $\mathrm{C}_{60} / \mathrm{CuPc}$ growth cycles, $n$. c) External quantum efficiency $\left(\eta_{\mathrm{EQE}}\right)$ spectra of devices with different $n$. d) Power conversion efficiency $\left(\eta_{\mathrm{P}}\right)$ as a function of $n$ and $\mathrm{C}_{60} /$ CuPc nanocrystalline layer thickness.

tangled heterointerface shows the same large EQE at zero bias, implying success in achieving continous conductive pathways. The EQE decreases at larger $n$ owing to a lower carrier collection efficiency resulting from increased resistance, possibly indicating that the percolating conducting paths formed by the network of nanocrystallites are interrupted by bottlenecks or islands. Note that the broad peak corresponding to $\mathrm{C}_{60}$ absorption shifts to shorter wavelength as $n$ increases, as a result of the optical field changes with the thickness.

Previously, it was shown that the growth of an organized interdigitated DA interface results in a 2.7 times increase in efficiency in a CuPc/PTCBI solar cell ${ }^{[8]}$ over its planar analog, but that architecture showed no improvement when the $\mathrm{CuPc} / \mathrm{C}_{60}$ system was used. ${ }^{[9]}$ This lack of improvement was attributed to the long $(\sim 40 \mathrm{~nm})$ exciton diffusion length ${ }^{[2]}$ in $\mathrm{C}_{60}$, which exceeded the interdigitated feature width. The $\mathrm{CuPc/PTCBI}$ cell characteristic diffusion lengths were $<10 \mathrm{~nm}$, or half of the feature size, hence leading to the efficiency improvement observed. In contrast, the photoresponse of $\mathrm{CuPc}$ and $\mathrm{C}_{60}$ in the nanocrystalline cells both increase by more than 3 times, suggesting that the high carrier mobility in the extended, percolating networks is primarily responsible for their improvement in efficiency.

The power conversion efficiency, $\eta_{\mathrm{p}}$, is plotted as a function of $n$ in Figure 5d. The photocurrent and power efficiencies of unpackaged devices were measured in air referenced to an NREL-calibrated Si detector. Here, $\eta_{\mathrm{p}}=1.4 \pm 0.1 \%$ in the bilayer device $(n=0)$ increases by a factor of 3 , to a maximum of $4.4 \pm 0.2 \%$ at $n=6$, corresponding to a total thickness of the nanocrystalline region of $38 \mathrm{~nm}$, which is almost double the optimum thickness of a mixed CuPc: $\mathrm{C}_{60}$ solar cell active region. ${ }^{[5]}$ The efficiency rolls off to $2.1 \pm 0.1 \%$ at $n=12$. The power efficiency of the unoptimized $\mathrm{CuPc} / \mathrm{C}_{60}$ bilayer control cell is consistent with that reported by other groups, ${ }^{[30,31]}$ although it is not as high as the best reported for planar cells using the same materials system grown by vacuum thermal evaporation. ${ }^{[26]}$ The solar cell efficiency showed minor ( $5 \%)$ degradation when exposed to ambient for 24 hours.

By controlling the organic molecule crystallization conditions, we used OVPD to deposit an organic solar cell architecture incorporating an all-organic nanocrystalline network which has both a large DA HJ interface area favorable for exciton dissociation, and a large thickness for light absorption. ${ }^{[32]}$ The crystalline order introduces only a small series resistance with increasing thickness, and our demonstration has resulted in a three-fold increase of efficiency over planar HJ controls in a one-to-one comparison. The solar cell active region thicknesses are $>100 \mathrm{~nm}$, eliminating shorts commonly observed in thinner cells, while also increasing the active region thickness, leading to an exponential increase in light absorption. Furthermore, changing the nanocrystalline size,${ }^{[8,9]}$ varying the DA ratio, ${ }^{[22]}$ incorporating more than two molecular components to obtain broader coverage of the solar spectrum, and employing multiple cells in a tandem structure ${ }^{[18]}$ may lead to even higher efficiencies. We emphasize that the devices reported here do not represent a practical demonstration, which would only be possible with large solar cell modules with long operational lifetimes. Rather, our work demonstrates that control of the fully organic nanostructure morphology leads to highly interconnected nanocrystalline networks that significantly improve both exciton dissociation and charge collection that have potential application to a new generation of solar energy conversion devices.

\section{Experimental}

The organic source material: $\mathrm{CuPc}, \mathrm{C}_{60}$, and $\mathrm{BCP}$ were purified by gradient sublimation prior to use. The films were deposited on a $300 \mathrm{~nm}$ thick ITO-coated glass substrate (Nippon Sheet Glass Co.), 
precleaned with organic solvents and exposed to ultraviolet/ozone before loading into the OVPD chamber [8,9] with a base pressure $<0.09$ Torr. OVPD employed a continuous flow of purified $\mathrm{N}_{2}$ through the organic source barrels regulated with mass flow controllers and a throttle valve. The substrate temperature $T_{\text {sub }}$ was kept constant at $15 \pm 0.5^{\circ} \mathrm{C}$ for all growth. The conditions for the growth of the first $\mathrm{CuPc}$ continuous layer were: source temperature, $T_{\mathrm{CuPc}}=446 \pm 1{ }^{\circ} \mathrm{C} ; \mathrm{N}_{2}$ flow rate $=150 \mathrm{sccm}$; reactor pressure $P=0.587 \pm 0.001$ Torr; and growth time $t_{\mathrm{g}}=1 \mathrm{~min}$. The conditions for the last $\mathrm{C}_{60}$ planarizing layer were: $T_{\mathrm{C} 60}=471 \pm 2{ }^{\circ} \mathrm{C}, \mathrm{N}_{2}$ flow rate $=100 \mathrm{sccm}, P=0.421 \pm 0.001$ Torr, and $t_{\mathrm{g}}=7 \mathrm{~min}$. For the discontinuous $\mathrm{CuPc}$ and $\mathrm{C}_{60}$ nano-crystallite growth the source temperatures were: $T_{\mathrm{CuPc}}=420 \pm 1{ }^{\circ} \mathrm{C}, T_{\mathrm{C} 60}=463 \pm 2{ }^{\circ} \mathrm{C}$, respectively. The thickness of each layer grown by OVPD is limited by quickly switching the carrier gas flow on and off through the two molecular source barrels (Fig. 1b, inset). Constant $\mathrm{N}_{2}$ flow at $20 \mathrm{sccm}$ through the $\mathrm{CuPc}$ or $\mathrm{C}_{60}$ molecular source barrels was used during deposition, with the same $\mathrm{N}_{2}$ flow used for $9 \mathrm{~s}$ between the switching of $\mathrm{C}_{60}$ and $\mathrm{CuPc}$ to minimize material mixing of the $\mathrm{D}$ and $\mathrm{A}$ molecules in the chamber prior to deposition.. The constant flow results in a stable pressure of $0.166 \pm 0.007$ Torr during the growth (see Fig. 1b). In each $\mathrm{C}_{60} / \mathrm{CuPc}$ cycle, $\mathrm{C}_{60}$ was deposited at a rate of $0.14 \pm 0.01 \mathrm{~nm} \mathrm{~s}^{-1}$ and CuPc was deposited at a rate of $0.25 \pm 0.01 \mathrm{~nm} \mathrm{~s}^{-1}$, calibrated from previous growth runs where the product film thicknesses were measured using ellipsometry. Cone-shape stoppers were used at the barrel nozzle exit ports to prevent organics from diffusing into the chamber when the source flow is off. After $\mathrm{CuPc} / \mathrm{C}_{60}$ growth, the samples were transferred through a $\mathrm{N}_{2}$ glove-box into a vacuum chamber where a $10 \mathrm{~nm}$ thick BCP layer, and the $100 \mathrm{~nm}$ thick $\mathrm{Ag}$ cathode were deposited using thermal evaporation at a pressure less than $4 \times 10^{-7}$ Torr through a shadow mask with an array of $1 \mathrm{~mm}$ diameter circular openings.

For the cross-sectional TEM, a $100 \mathrm{~nm}$ thick Au layer was deposited on top of the organic films to protect the organic during the thinning process. Two such pieces were glued together face-to-face. The sample was then ground, polished, and thinned to less than $100 \mathrm{~nm}$ by ion milling. A $200 \mathrm{kV}$ JEOL JEM2010F STEM/TEM was used for high-resolution electron microscopy and high-angle annular dark-field imaging. SAED was used for plan-view organic films pealed off from the substrates. The SAED diffraction was calibrated to Au sample and the calculated lattice constants matches literature values with errors $<5 \%$ for $\alpha$-CuPc [33] and $<2.5 \%$ for $\mathrm{C}_{60}$ [21]. The absorption spectra were measured using a Perkin-Elmer Lambda 800 UV/vis spectrometer for samples grown on fused quartz substrates.

Solar cell performance was tested in ambient conditions in air without encapsulation. To measure the EQE, a monochromatic beam of light from a Xe-lamp was chopped at $400 \mathrm{~Hz}$ and focused to a spot on the $1 \mathrm{~mm}$ diameter device. The light intensity was measured using a NREL-standard calibrated $\mathrm{Si}$ solar cell, and photocurrent spectra were measured using a lock-in amplifier referenced to the chopper frequency [27]. The $J-V$ characteristics and power-conversion efficiencies of the devices were measured using an Oriel $150 \mathrm{~W}$ solar simulator equipped with AM1.5G filters (Newport). We also checked the solar spectral mismatch factor, $M$, using AM $1.5 \mathrm{G}$ spectra, the simulation illumination spectra and the photoresponsivity of reference cell, yielding $M \sim 1$. The difference between measured and spectrally corrected $J_{\mathrm{SC}}$ are within the errors of our measurements.

Received: April 8, 2007

Revised: August 3, 2007

Published online: October 26, 2007

[1] C. W. Tang, Appl. Phys. Lett. 1986, 48, 183.

[2] P. Peumans, A. Yakimov, S. R. Forrest, J. Appl. Phys. 2003, 93, 3693.
[3] W. Ma, C. Yang, X. Gong, K. Lee, A. J. Heeger, Adv. Funct. Mater. $\mathbf{2 0 0 5}, 15,1617$.

[4] B. P. Rand, J. Xue, S. Uchida, S. R. Forrest, J. Appl. Phys. 2005, 98 , 124902

[5] J. Xue, B. P. Rand, S. Uchida, S. R. Forrest, Adv. Mater. 2005, 17, 66.

[6] W. U. Huynh, J. J. Dittmer, A. P. Alivisatos, Science 2002, 295, 2425.

[7] B. Sun, H. J. Snaith, A. S. Dhoot, S. Westenhoff, N. C. Greenham, J. Appl. Phys. 2004, 97, 014914.

[8] F. Yang, M. Shtein, S. R. Forrest, Nat. Mater. 2005, 4, 37

[9] F. Yang, M. Shtein, S. R. Forrest, J. Appl. Phys. 2005, 98, 014906.

[10] R.-F. Xiao, J. I. D. Alexander, F. Rosenberger, Phys. Rev. A 1991, 43 , 2977.

[11] D.-J. Liu, R. L. B. Selinger, J. D. Weeks, J. Chem. Phys. 1996, 105, 4751.

[12] V. P. Antropov, O. Gunnarsson, O. Jepsen, Phys. Rev. B 1992, 46, 13647.

[13] R. W. Lof, M. A. van Veenendaal, B. Koopmans, H. T. Jonkman, G. A. Sawatzky, Phys. Rev. Lett. 1992, 68, 3924.

[14] M. Fendrich, T. Wagner, M. Stohr, R. Moller, Phys. Rev. B 2006, 73, 115433.

[15] G. Li, V. Shrotriya, J. Huang, Y. Yao, T. Moriarty, K. Emery, Y. Yang, Nat. Mater. 2005, 4, 864.

[16] V. Bhosle, J. T. Prater, F. Yang, D. Burk, S. R. Forrest, J. Narayan, J. Appl. Phys. 2007, 102, 023501.

[17] J. R. Fryer, J. Electron Microsc. Tech. 1989, 11, 310.

[18] B. Maennig, J. Drechsel, D. Gebeyehu, P. Simon, F. Kozlowski, A. Werner, F. Li, S. Grundmann, S. Sonntag, M. Koch, K. Leo, M. Pfeiffer, H. Hoppe, D. Meissner, N. S. Sariciftci, I. Riedel, V. Dyakonov, J. Parisi, Appl. Phys. A 2004, 79, 1.

[19] P. Simon, B. Maennig, H. Lichte, Adv. Funct. Mater. 2004, 14, 669.

[20] C. C. Leznoff, A. B. P. Lever, Phthalocyanines: Properties and Applications, VCH, New York 1989.

[21] P. A. Heiney, J. E. Fischer, A. R. McGhie, W. J. Romanow, A. M. Denenstein, J. P. McCauley Jr., A. B. Smith, D. E. Cox, Phys. Rev. Lett. 1991, 66, 2911.

[22] P. Sullivan, S. Heutz, S. M. Schultes, T. S. Jones, Appl. Phys. Lett. 2004, 84, 1210.

[23] S. Heutz, P. Sullivan, B. M. Sanderson, S. M. Schultes, T. S. Jones, Sol. Energy Mater. Sol. Cells 2004, 83, 229.

[24] P. Peumans, S. Uchida, S. R. Forrest, Nature 2003, 425, 158.

[25] P. Peumans, S. R. Forrest, Appl. Phys. Lett. 2001, 79, 126.

[26] J. Xue, S. Uchida, B. P. Rand, S. Forrest, Appl. Phys. Lett. 2004, 84, 3013.

[27] Standard ASTM E1021-95, Standard Test Methods for Measuring Spectral Response of Photovoltaic Cell, American Society for Testing and Materials, West Conshohocken, PA, USA 2001.

[28] S. Mochizuki, M. Sasaki, R. Ruppin, J. Phys. Condens. Matter 1998, 10, 2347.

[29] P. Peumans, V. Bulovic, S. R. Forrest, Appl. Phys. Lett. 2000, 76 , 3855.

[30] K. Fostiropoulos, M. Vogel, B. Mertesacker, A. Weidinger, Proc SPIE-Int. Soc. Opt. Eng. 2003, 4801, 1.

[31] Z. R. Hong, C. J. Liang, X. Y. Sun, X. T. Zeng, J. Appl. Phys. 2006 $100,93711$.

[32] Note added in review: Analogous but not identical structures utilizing ultrathin organic layers grown by vacuum evaporation also show a modest improvement of power conversion efficiency: Z. R. Hong, B. Maennig, R. Lessmann, M. Pfeiffer, K. Leo, P. Simon, Appl. Phys. Lett. 2007, 90, 203505.

[33] P. Erk, H. Hengelsberg, in Applications of Phthalocyanines, Vol. 19 (Eds: K. M. Kadish, K. M. Smith, R. Guilard), Elsevier, New York 2003, p. 105. 